\title{
Use of a double epidural catheter provides effec- tive postoperative analgesia after spine deformity surgery
}

\author{
[L'utilisation d'un double cathéter péridural fournit une analgésie postopératoire \\ efficace après une opération pour déformation de la colonne vertébrale]
}

Georgios Ekatodramis MD, ${ }^{*}$ Kan Min MD,$\dagger$ Philipp Cathrein MD,$\dagger$ Alain Borgeat MD*

Purpose: Spine deformity surgery is a painful procedure in which pain control is difficult to obtain. The aim of this study was to evaluate the efficacy of double epidural catheters in this setting.

Methods: Twenty-three patients scheduled for an elective spine deformity surgery were included prospectively. At the end of surgery, the surgeon inserted two epidural catheters, one cranial, one caudal to the surgical field. In the recovery room the catheters were both injected with a bolus of bupivacaine $0.0625 \%$. In the absence of any neurological abnormality a continuous infusion of bupivacaine $0.0625 \%$, fentanyl $2 \mu \mathrm{g} \cdot \mathrm{mL}^{-1}$ and clonidine $3 \mu \mathrm{g} \cdot \mathrm{mL}^{-1}$ was administered at a rate of $10 \mathrm{~mL} \cdot \mathrm{hr}^{-1}$ through each catheter for $48 \mathrm{hr}$. Pain score, sedation level, motor block and side-effects were checked regularly.

Results: Complete analgesia (VAS $=0$ ) was obtained at rest in all patients. During mobilization and physiotherapy four patients ( I7\%) had a VAS 30. No motor block was observed. Four patients ( $17 \%)$ had nausea and vomiting. No excessive sedation, pruritus or respiratory depression were observed. Early mobilization was possible in all patients.

Conclusion: Postoperative epidural analgesia by means of a double catheter is an effective technique to control pain after spine deformity surgery and is associated with a low incidence of sideeffects.

Objectif : La correction d'une déformation de la colonne vertébrale est douloureuse et difficile à soulager. Notre étude voulait évaluer, dans ce cas, l'efficacité de deux cathéters.

Méthode : Vingt-trois patients devant subir une intervention non urgente pour déformation à la colonne vertébrale ont participé à l'étude prospective. À la fin de l'opération, le chirurgien a inséré deux cathéters périduraux, l'un au-dessus, l'autre en dessous du champ opératoire. À la salle de réveil, on a injecté un bolus de bupivacaïne à 0,0625\% dans chaque cathéter. En l'absence de toute anomalie neurologique, une perfusion continue de bupivacaïne à $0,0625 \%$, de $2 \mu \mathrm{g} \cdot \mathrm{mL}^{-1}$ de fentanyl et de $3 \mu \mathrm{g} \cdot \mathrm{mL}^{-1}$ de clonidine a été administrée dans chaque cathéter, à raison de $10 \mathrm{~mL} \cdot \mathrm{hr}^{-1}$ pendant $48 \mathrm{~h}$. Les scores de douleur, le niveau de sédation, la présence de blocage moteur et les effets secondaires ont été notés régulièrement.

Résultats : L'analgésie complète $(E V A=0)$ a été obtenue au repos chez tous les patients. Pendant le mouvement et la physiothérapie, quatre patients, (17\%) ont présenté un score 30 à l'EVA. Aucun blocage moteur n'a été observé. Quatre patients (17\%) ont eu des nausées et des vomissements. Ni la sédation excessive, ni le prurit ou la dépression respiratoire n'ont été observés. La mobilisation précoce a été possible chez tous les patients.

Conclusion : L'utilisation de deux cathéters pour administrer l'analgésie péridurale assure un contrôle efficace de la douleur après la correction d'une déformation de la colonne vertébrale et présente peu d'effets secondaires.

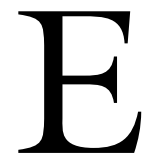

PIDURAL analgesia with local anesthetics and/or opioids is performed routinely after major surgical procedures including thoracic, abdominal and orthopedic surgery. ${ }^{1-3}$ Epidural analgesia has proven to be superior to conventional $i v$ analgesia, providing better quality of pain control and reducing side-effects like sedation, nausea, vomiting, pulmonary, cardiac and gastrointestinal dysfunction. ${ }^{1}$ Spine deformity surgery comprises an anterior soft tissue release through thoracotomy, followed

From the Departments of Anesthesiology, ${ }^{*}$ and Orthopedic Surgery, $†$ Orthopedic University Hospital Zurich/Balgrist, Zurich, Switzerland.

Address correspondence to: Dr. Alain Borgeat, Chief of Staff Anesthesiology, University Clinic of Zurich/Balgrist, Forchstrasse 340, CH8008 Zurich, Switzerland. Phone: +41 138611 11; Fax: +41 1386 16 09; E-mail: aborgeat@balgrist.unizh.ch

Accepted for publication August 28, 2001.

Revision accepted November 12, 2001. 
by posterior spinal fusion, which requires a large incision to expose most of the thoracolumbar spine, resulting in severe postoperative pain. ${ }^{4,5}$ Moreover, spinal deformity surgery is most frequently performed in children and adolescents, who are known to be more sensitive to pain than adults. ${ }^{6}$ Epidural analgesia in this clinical setting appears to be an elegant solution, since excellent pain relief can be expected not only at rest, but also during respiratory physiotherapy. The feasibility and efficacy of epidural analgesia after posterior spinal surgery was recently described by Turner $e t a l .{ }^{7}$ but in this study the use of a single epidural catheter did not provide adequate pain relief in all patients. The aim of our study was to re-evaluate the feasibility and efficacy of epidural analgesia after spine deformity surgery by using two epidural catheters.

Materials and methods

After approval by the Ethics Committee and written informed consent from the patients had been obtained, we prospectively included 23 adolescents of both sexes (classified as ASA physical status I-III), scheduled for elective spine deformity surgery (idiopathic or neurological scoliosis) with a combined ventrodorsal approach. Thoracotomy was performed by subperiostal resection of either the sixth or seventh rib depending on the level of spine deformity. Pedicular instrumentation (without laminectomies and disruption of the epidural space) was used in all patients. Exclusion criteria were known allergy to one of the trial drugs, pregnancy, preoperative neurological disturbances and inability to quantify pain on a visual analogue scale (VAS). All patients were premedicated with midazolam $0.1 \mathrm{mg} \cdot \mathrm{kg}^{-1}$ po one hour before anesthesia. Anesthesia was induced with propofol 2.5-4 $\mathrm{mg} \cdot \mathrm{kg}^{-1}$ and maintained with $8-10 \mathrm{mg} \cdot \mathrm{kg}^{-1} \cdot \mathrm{hr}^{-1}$. Endotracheal intubation was facilitated by rocuronium $0.8 \mathrm{mg} \cdot \mathrm{kg}^{-1}$. Analgesia during surgery was provided with boli of fentanyl 1-2 $\mu \mathrm{g} \cdot \mathrm{kg}^{-1}$ as necessary. Continuous intraoperative neurological monitoring was assessed by somatosensory evoked potentials (SSEP). ${ }^{8}$ Just before wound closure the surgeon accessed the epidural space through the ligamentum flavum of the appropriate level with the use of a Tuohy needle (loss of resistance technique). Two epidural catheters (Portex, Hythe, Kent, UK epidural catheter $20 \mathrm{G}$ ) were inserted $4-5 \mathrm{~cm}$ into the epidural space at the cranial and caudal end of the surgical field (cranial between thoracic levels T4 and T6 and caudal between T10 and L1). The correct placement of the epidural catheter was checked radiologically. After injecting each catheter with $3 \mathrm{~mL}$ contrast medium (Iopamiro ${ }^{\circledR}$, Bracco s.p.a. Milano, Italy) an anterior- posterior and a lateral $x$-ray of the spine was obtained. The $x$-ray was assessed by a consultant radiologist with special attention to presence, site and spread of contrast medium. After recovery from general anesthesia, the patients were transferred to the intensive care unit, where a complete neurological examination was performed. Patients showing any neurological disorders were excluded from the study. In the absence of any neurological disturbance, continuous epidural analgesia was initiated two hours later. Before epidural analgesia was started, pain was treated with repeated boli of morphine $2 \mathrm{mg}$ iv as requested by patients. To check the efficacy of the epidural catheters, they were injected initially with a bolus of bupivacaine $0.0625 \%$, $8 \mathrm{~mL}$ for patients weighing more than $50 \mathrm{~kg}$ or $5 \mathrm{~mL}$ for those less than $50 \mathrm{~kg}$, through each catheter. Placement of the epidural catheters was considered adequate if homogeneous sensory anesthesia (cold test) covering at least the spinal segments from T4 to T12 was achieved. Thereafter, two infusion pumps (IVAC P 4000, Welmed, Hampshire, UK) were used to perfuse both epidural catheters with a mixture of bupivacaine $0.0625 \%$, fentanyl $2 \mu \mathrm{g} \cdot \mathrm{mL}^{-1}$ and clonidine $3 \mu \mathrm{g} \cdot \mathrm{mL}^{-1}$ at a rate of $10 \mathrm{~mL} \cdot \mathrm{hr}^{-1}$ each. Pain was assessed at rest, every six hours and during respiratory physiotherapy or mobilization at 24 and $48 \mathrm{hr}$ by means of a VAS ranging from $0=$ no pain to $100=$ worst pain imaginable. If pain was not controlled adequately (pain score $>30$ on the VAS), analgesia was first completed with $i v$ proparacetamol (maximum $6 \times 2 \mathrm{~g}$ $i v /$ day) and if necessary with $i v$ morphine ( $2 \mathrm{mg}$ boli) according to patient request. Respiratory function was monitored continuously by means of pulse oximetry and respiratory frequency. A chest radiography was performed every day.

Motor function of the lower limbs was assessed by the patients' ability to flex the knees and ankles every hour for the first postoperative day and then every six hours for the following $24 \mathrm{hr}$. Motor block was evaluated by means of a modified four-grade Bromage scale: ${ }^{9}$ $0=$ no paralysis; $1=$ inability to lift the thigh (just able to move knee and feet); 2 =inability to flex knee (able to move feet); 3 =inability to move any joint in the legs, every hour during the first postoperative day and then every six hours during the following $24 \mathrm{hr}$. If a motor block of more than 1 on the Bromage scale occurred, if oxygen saturation was less than 92 or if respiratory frequency was less than $8 \cdot \mathrm{min}^{-1}$, the epidural infusion was stopped and pain treatment continued with morphine iv patient controlled analgesia (PCA). Sedation was assessed every six hours using the following score: $0=$ wide awake; $1=$ drowsy, but easily aroused to an alert state by verbal command; $2=$ dozing intermittently, but 
aroused by verbal command; $3=$ mostly sleeping, but aroused to a drowsy state by light tactile stimulation. If a sedation score of 3 occurred epidural analgesia was stopped. The appearance of nausea, vomiting, pruritus, cardiac and pulmonary complications was recorded. Cardiac complications were defined as a decrease of mean arterial pressure of more than $20 \%$ compared to the preoperative value or the occurrence of cardiac arrhythmias (bradycardia, atrial fibrillation). Pulmonary complications were defined as: respiratory rate less then $8 \cdot \mathrm{min}^{-1}$, oxygen saturation less then $92 \%$, apparent lobar atelectasis on chest $x$-ray. Forty-eight hours postoperatively epidural analgesia was stopped and analgesia was continued with patient controlled iv analgesia with morphine (PCIVA).

For this study, only a descriptive statistical analysis was performed. Values are expressed as mean \pm SD.

Results

The study included 12 female and 11 male patients, age $12-19$ yr (median 15) weighing $30-55 \mathrm{~kg}$ (median 45). Underlying conditions included: idiopathic scoliosis $(n=20)$, Duchenne muscular dystrophy $(n=2)$, M. Recklinghausen $(n=1)$. Duration of surgery was $360 \pm 36 \mathrm{~min}$. No surgical problems were observed. Epidural spread of contrast medium was seen in all catheters (Figure). Perioperative monitoring of neurological function did not show any abnormalities. Postoperative neurological examination was normal in all patients and no patient was excluded. After the epidural bolus injection, all patients developed a homogenous spread of sensory anesthesia over the trunk. The highest cranial sensory level measured was Tl and the most caudal was at Ll. No patient showed any motor blockade, neither after the epidural bolus administration nor during the continuous epidural infusion until the end of the study ( $48 \mathrm{hr}$ ). Complete analgesia was obtained at rest in all patients. During mobilization and respiratory physiotherapy 19 patients had sufficient analgesia (Table), while four patients had a VAS $>30$ and requested supplementary analgesics. Each patient received $3 \times 2 \mathrm{mg}$ morphine intravenously until the end of the study. Oxygen saturation remained above $92 \%$ in all patients except one who required reintubation. No episode of respiratory depression was observed otherwise. During the first three postoperative hours the patients needed on average $5 \pm 2 \mathrm{mg}$ morphine per hour. Except for the four patients who experienced excessive pain on mobilization, no patient needed supplementary morphine.

Early mobilization at the bed side was possible in 22 patients on the second postoperative day. Sedation score was either 0 or 1 in 21 patients. Two patients

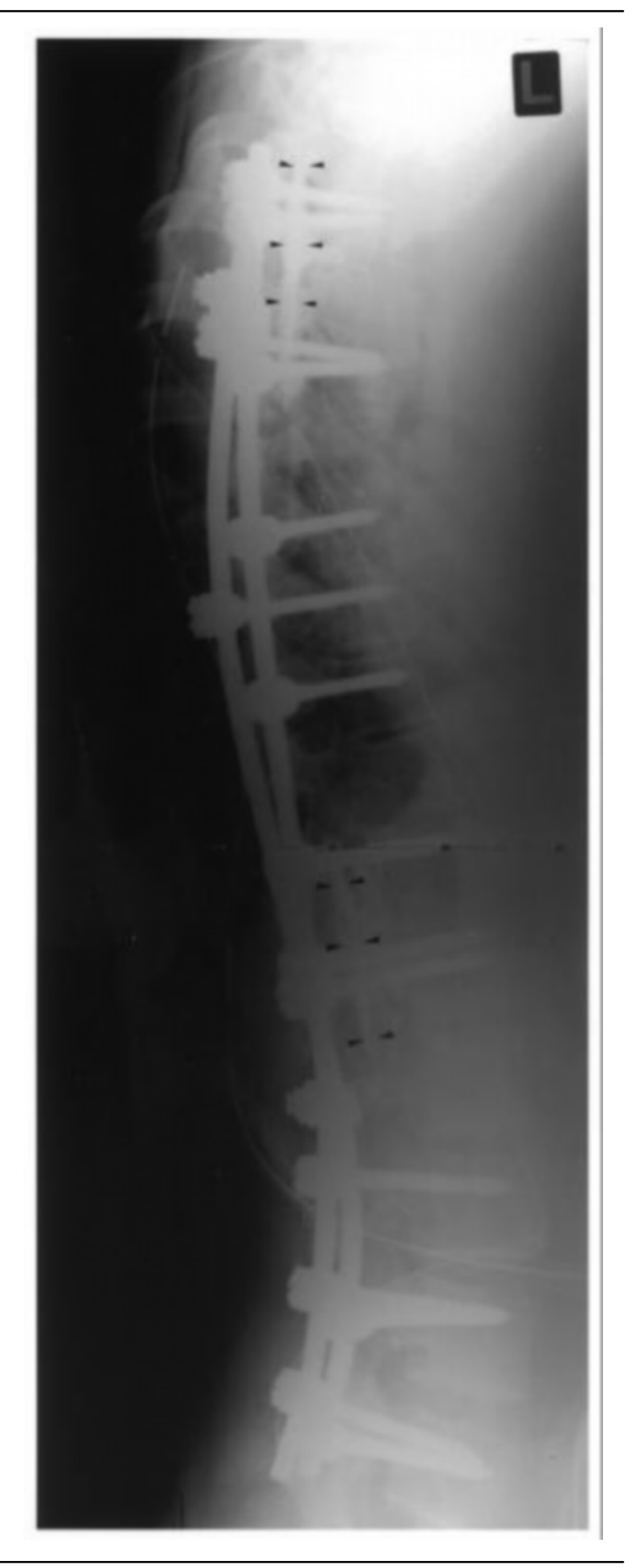

FIGURE Postoperative standard lateral radiography of the spine demonstrating contrast medium within the epidural space (arrows); $3 \mathrm{~mL}$ contrast medium (Iopamiro ${ }^{\circledR}$ ) was injected simultaneously through two epidural catheters, which were inserted intraoperatively (one at the thoracic and one at the lumbar level) following spine deformity surgery. 
TAB LE Postoperative pain scores (0-100 visual analogue scale) during continuous epidural analgesia with a dual catheter technique following spine deformity surgery

\begin{tabular}{lll}
\hline $\begin{array}{l}\text { Time (br) after } \\
\text { start of treatment }\end{array}$ & Pain score at rest & $\begin{array}{l}\text { Pain score during } \\
\text { physiotherapy }\end{array}$ \\
\hline 6 & $0 \pm 4$ & \\
12 & $0 \pm 3$ & \\
18 & $0 \pm 5$ & $15 \pm 2$ \\
24 & $0 \pm 3$ & \\
30 & $0 \pm 7$ & \\
36 & $0 \pm 5$ & $12 \pm 4$ \\
42 & $0 \pm 6$ & \\
48 & $0 \pm 4$ & \\
\hline
\end{tabular}

Values are mean \pm SD.

had a sedation score of 2 . No sedation score of 3 was observed. No cardiac or pulmonary complications were noted except in one patient, a 12-yr-old boy (neurologic scoliosis due to Duchenne muscular dystrophy) who had to be intubated on the second postoperative day because of bilateral pleural effusions. $\mathrm{He}$ had bilateral thoracic drainage and recovered uneventfully. Four patients had nausea or vomiting (17\%) within the first 24 postoperative hours and all were successfully treated with tropisetron. Symptoms of ileus or other intestinal complications were not observed. No patient complained of pruritus.

\section{Discussion}

After spine deformity surgery, continuous epidural analgesia with two epidural catheters provides excellent analgesia when a mixture of bupivacaine $0.0625 \%$ with fentanyl $2 \mu \mathrm{g} \cdot \mathrm{mL}^{-1}$ and clonidine $3 \mu \mathrm{g} \cdot \mathrm{mL}^{-1}$ is perfused at a rate of $10 \mathrm{~mL} \cdot \mathrm{hr}^{-1}$ through each catheter during $48 \mathrm{hr}$, with a low incidence of side-effects and a high degree of patient satisfaction.

Single or double epidural catheters placed intraoperatively have been used in the past to provide epidural analgesia after spine surgery. ${ }^{10,11}$ Shaw et al. ${ }^{12}$ showed the effectiveness of continuous epidural analgesia with opioids and local anesthetics for pain control after spine deformity surgery in children and adolescents. In a similar population Arms et al. ${ }^{13}$ confirmed the effectiveness of this analgesic technique. Joshi et al. ${ }^{14}$ further demonstrated in adults that epidural fentanyl infusion after lumbar laminectomy provided greater analgesia with fewer side-effects than morphine iv PCA. Cohen et al. ${ }^{15}$ on the other hand, could not find significant differences in the effectiveness of postoperative continuous epidural analgesia vs PCA after lumbar spine fusion. However, this study group did not define a dose regimen for the epidural infusion. In a more recent work Turner et al. ${ }^{7}$ have demonstrated that surgically placed single epidural catheters for analgesia after posterior spinal fusion can result in successful pain relief with the administration of a mixture containing bupivacaine $0.1 \%$ and fentanyl $5 \mu \mathrm{g} \cdot \mathrm{mL}^{-1}$ at a rate of $0-15 \mathrm{~mL} \cdot \mathrm{hr}^{-1}$. Only catheters verified radiologically to lie in the epidural space provided adequate pain control, but supplementary epidural boli were necessary to maintain analgesia. Spine deformity surgery often requires the exposure of the whole thoracolumbar spine. To provide effective epidural analgesia for such a large surgical field, the spread of epidural drugs to the desired nerve roots is crucial. Clinical experience with the use of continuous epidural infusions delivered through a single epidural catheter placed at the mid-level of the surgical procedure has shown that many patients with incomplete analgesia experienced pain localized to the upper or lower parts of the surgical field. ${ }^{16}$ Tobias et al. ${ }^{16}$ investigated the efficacy of a dual epidural catheter technique in providing analgesia following posterior spinal fusion in children. After a bolus injection of ropivacaine $0.2 \%\left(0.2 \mathrm{~mL} \cdot \mathrm{kg}^{-1}\right.$ into the lower catheter and $0.1 \mathrm{~mL} \cdot \mathrm{kg}^{-1}$ into the upper catheter) a continuous infusion of ropivacaine $0.1 \%$ plus hydromorphone 10 $\mu \mathrm{g} \cdot \mathrm{mL}^{-1}$ at a rate of $0.2 \mathrm{~mL} \cdot \mathrm{kg}^{-1} \cdot \mathrm{hr}^{-1}$ for the lower catheter and $0.1 \mathrm{~mL} \cdot \mathrm{kg}^{-1} \cdot \mathrm{hr}^{-1}$ for the upper catheter was initiated. Although the technique was effective, many of their patients still had episodes of significant pain and needed additional epidural boluses. This is in contrast with our results and may be explained by the different drugs (bupivacaine vs ropivacaine), infusion rates and adjuncts (hydromorphone $v s$ fentanyl/clonidine) used in our study. Technical differences in inserting the catheter may also explain our results and those observed by Tobias. Compared to our technique (Tuohy needle), Tobias et al. removed a portion of the ligamentum flavum in order to insert the epidural catheters. We believe that this "opening of the epidural space" would allow the drugs to escape from the epidural space, possibly explaining the relatively high percentage of insufficient analgesia.

Epidural analgesia, compared to other types of postoperative pain control, has many advantages. This technique reduces the need for iv opioids, thereby decreasing the incidence and severity of adverse effects such as nausea/vomiting, sedation, bowel paralysis and respiratory depression. ${ }^{1}$ Seventeen percent of the patients in the present study had nausea or vomiting within the first postoperative day. Eighty percent of these occurred within the first three hours following extubation and may be related to the administration of iv morphine while epidural analgesia was still not acti- 
vated. However, the administration of fentanyl given through the epidural catheter may also be implicated. ${ }^{17}$ There was no report of pruritus despite relatively large doses of epidural fentanyl. This contrasts with the findings of Arms ${ }^{13}$ and Shaw, ${ }^{12}$ who reported an incidence of pruritus ranging from $27 \%$ to $40 \%$, but they used morphine instead of fentanyl in their epidural solutions.

Excellent pain control allowed early intensive physiotherapy and mobilization in all patients. No pulmonary complication was observed, except in one patient with Duchenne's muscular dystrophy who had to be reintubated on the second postoperative day. We suspect the muscular dystrophy to be the underlying etiology factor because pain was well controlled and no decrease in respiratory drive or excessive sedation was observed.

This study may be criticized since we had no control group, but our primary aim was to show the feasibility of this particular technique, rather than to compare it with a conventional approach. Our data suggest that this technique results in successful pain relief, allowing early and efficient respiratory physiotherapy, but further studies will be needed to confirm its efficacy in this clinical setting. In conclusion, we have shown that postoperative epidural analgesia by means of a double catheter is an effective technique to control pain after spine deformity surgery and is associated with a low incidence of side-effects.

\section{References}

1 Liu S, Carpenter RL, Neal JM. Epidural anesthesia and analgesia. Their role in postoperative outcome. Anesthesiology 1995; 82: 1474-506.

2 Chisakuta AM, George KA, Hawthorne CT.

Postoperative epidural infusion of a mixture of bupivacaine $0.2 \%$ with fentanyl for upper abdominal surgery. A comparison of thoracic and lumbar routes. Anaesthesia 1995; 50: 72-5.

3 Lubenow TR, Faber LP, McCarthy RJ, Hopkins EM, Warren WH, Ivankovich AD Postthoracotomy pain management using continuous epidural analgesia in 1,324 patients. Ann Thorac Surg 1994; 58: 924-30.

4 Melzack R, Abbott FV, Zackon W, Mulder DS, Davis $M W$. Pain on a surgical ward: a survey of the duration and intensity of pain and the effectiveness of medication. Pain 1987; 29: 67-72.

5 Spence AA Pain after surgery. J Bone Joint Surg Br 1991; 73: 189-90.

6 Johnston CC, Strada ME. Acute pain response in infants: a mutlidimensional description. Pain 1986; 24: 373-82.

7 Turner A, Lee J, Mitchell R, Berman J, Edge G, Fennelly $M$. The efficacy of surgically placed epidural catheters for analgesia after posterior spinal surgery. Anaesthesia 2000; 55: 367-90.

8 Loughnan BA, Fennelly ME, Henley M, Hall GM. The effects of differing concentrations of bupivacaine on the epidural somatosensory evoked potential after posterior tibial nerve stimulation. Anesth Analg 1995; 81: 147-51.

9 Bromage PR A comparison of the hydrochloride and carbon dioxide salts of lidocaine and prilocaine in epidural analgesia. Acta Anaesthesiol Scand Suppl 1965; 16: 55-69.

10 Myint $O$ A double catheter epidural technique for major surgery (Letter). Anaesthesia 1976; 31: 574-6.

11 Schachner SM, Abram SE. Use of two epidural catheters to provide analgesia of unblocked segments in a patient with lumbar disc disease. Anesthesiology 1982; 56: 150-1.

12 Shaw BA, Watson TC, Merzel DI, Gerardi JA, Birek A The safety of continuous epidural infusion for postoperative analgesia in pediatric spine surgery. J Pediatr Orthop 1996; 16: 374-7.

13 Arms DM, Smith JT, Osteyee J, Gartrell A Postoperative epidural analgesia for pediatric spine surgery. Orthopedics 1998; 21: 539-44.

14 Joshi GP, McCarroll SM, O'Rourke K Postoperative analgesia after lumbar laminectomy: epidural fentanyl infusion versus patient-controlled intravenous morphine. Anesth Analg 1995; 80: 511-4.

15 Cohen BE, Hartman MB, Wade JT, Miller JS, Gilbert $R$, Chapman TM. Postoperative pain control after lumbar spine fusion. Patient-controlled analgesia versus continuous epidural analgesia. Spine 1997; 22: 1892-7.

16 Tobias JD, Gaines RW, Lowry KJ, Kittle D, Bildner C A dual epidural catheter technique to provide analgesia following posterior spinal fusion for scoliosis in children and adolescents. Paediatr Anaesth 2001; 11 : 199-203.

17 Scott DA, Beilby DS, McClymont C Postoperative analgesia using epidural infusions of fentanyl with bupivacaine. A prospective analysis of 1,014 patients. Anesthesiology 1995; 83: 727-37. 